Bulletin d'Histoire Contemporaine de I'Espagne

$54 \mid 2020$

Les espaces du politique dans l'Espagne du Trienio liberal (1820-1823)

\title{
Manuel Pérez Ledesma (1944-2018)
}

José Álvarez Junco, Universidad Complutense. Madrid, Santos Juliá y UNED. Madrid

\section{(2) OpenEdition}

1 Journals

Edición electrónica

URL: http://journals.openedition.org/bhce/3323

DOI: 10.4000/bhce.3323

ISSN: 1968-3723

Editor

Presses Universitaires de Provence

\section{Edición impresa}

Fecha de publicación: 1 enero 2020

ISSN: 0987-4135

Referencia electrónica

José Álvarez Junco, Universidad Complutense. Madrid, Santos Juliá y UNED. Madrid, « Manuel Pérez Ledesma (1944-2018)», Bulletin d'Histoire Contemporaine de l'Espagne [En línea], 54 | 2020, Publicado el 01 julio 2020, consultado el 31 diciembre 2020. URL : http://journals.openedition.org/bhce/3323 ; DOl : https://doi.org/10.4000/bhce.3323

Este documento fue generado automáticamente el 31 diciembre 2020.

Bulletin d'histoire contemporaine de l'Espagne 


\title{
Manuel Pérez Ledesma (1944-2018)
}

\author{
José Álvarez Junco, Universidad Complutense. Madrid, Santos Juliá y \\ UNED. Madrid
}

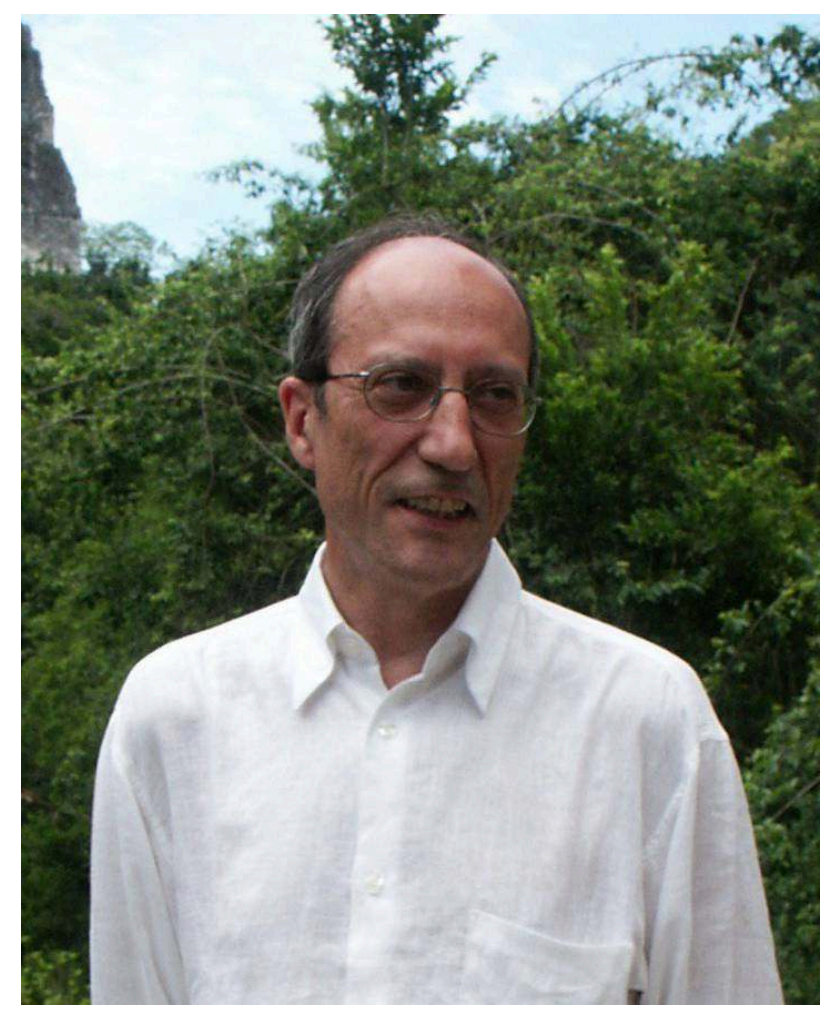

1 Manuel Pérez Ledesma reunió en su biografía un buen puñado de las experiencias que marcaron a los miembros política y socialmente más comprometidos de una generación de historiadores en los últimos años de la dictadura. Estudiante contestatario en la universidad y profesor ayudante procesado y condenado a cinco meses de arresto por su militancia en Comisiones Obreras, tuvo que abandonar Salamanca y doctorarse brillantemente en Madrid, para iniciar, de la mano de Javier Pradera, una fecunda carrera como editor en Historia y Ciencias Sociales de Alianza Editorial y, acogido por Miguel Artola, como profesor de Historia en la Universidad Autónoma. 
2 Aunque lo sabía todo sobre las primeras décadas de la UGT, Pérez Ledesma nunca publicó su tesis: su inteligencia y sentido crítico le hizo sentirse a disgusto con los tópicos entonces dominantes y dejó la publicación para más tarde, cuando tuviera tiempo para reelaborarla. Nunca lo tuvo, aunque la historia alternativa que llevaba en la cabeza quedó plasmada finalmente en algunos artículos seminales sobre las relaciones de poder y la organización interna del partido y del sindicato socialistas, en sus estudios sobre dirigentes como García Quejido y Llaneza, incisivos y desmitificadores como aquel ¿Pablo Iglesias, santo?, o en sus reflexiones sobre la supuesta tendencia revolucionaria del proletariado o el discutible protagonismo obrero en las revoluciones del siglo XX.

3 Su doble experiencia de editor y profesor durante un tiempo en el que las viejas certidumbres se derrumbaban y la historia elaborada al servicio de una causa dejaba paso a la historia como un saber del pasado siempre en discusión le equipó para abrir nuevos caminos a la investigación y nuevos espacios al permanente debate historiográfico.

4 Conociendo al detalle y publicando en España lo mejor de lo que aparecía fuera, y dotado, como muy pocos, para alentar trabajos en equipo, se convirtió en un incansable organizador de encuentros y seminarios, de los que salieron proyectos de obras colectivas sobre los nuevos movimientos sociales, el proceso de conquista de la ciudadanía o la historia de las culturas políticas en España y América, que tanto han influido en la renovación de la historiografía española. Todo ello apoyado siempre en un gran esfuerzo por conocer y manejar los conceptos fundamentales elaborados por las ciencias sociales, tan importantes para la obra de los historiadores y, sin embargo, tan débiles a veces en ella.

5 Manuel Pérez Ledesma fue un autor de excepcional originalidad, ironía y agudeza en el panorama historiográfico español. Pero fue, además, el amigo que siempre elegía el vino para la cena, el devorador de libros que siempre recomendaba la lectura más sabrosa, el que se arrancaba con alguna copla o algún corrido para animar la fiesta. Quienes tuvimos la fortuna de disfrutar durante décadas de su amistad, de su ingenio y de su gusto por la vida, y quienes la tuvieron de ser sus discípulos, sabemos bien lo que hemos perdido. 